\title{
THE CONCEPTUAL FRAMEWORK FOR THE RESOURCES MANAGEMENT ATTRIBUTES AND AIRCRAFT MAINTENANCE EFFICIENCY IN THE AVIATION INDUSTRIES IN OMAN
}

\author{
Said Hamed Al Rawahi \\ PhD Research Fellow \\ Faculty of Business and Accountancy \\ University of Selangor \\ 40000 Shah Alam, Selangor Darul Ehsan, Malaysia \\ E-mail: s_alrwahi@hotmail.com \\ Dr. Zaharuzaman Bin Jamaluddin \\ Senior Lecturer \\ Faculty of Business and Accountancy \\ University of Selangor \\ 40000 Shah Alam, Selangor Darul Ehsan, Malaysia \\ E-mail: zaharuzaman@unisel.edu.my \\ Dr. Abul Bashar Bhuiyan \\ Associate Professor \\ Faculty of Business and Accountancy \\ University of Selangor \\ 40000 Shah Alam, Selangor Darul Ehsan, Malaysia \\ E-mail: bashariuk@gmail.com
}

\begin{abstract}
The main purpose of the study is to investigate existing available literature for determining of relevant factors that have cause and effects on the ensuring of aircraft maintenance efficiency in the aviation industry in Oman. Therefore, the study uses available sources of existing literature based on the four main keywords 'aircraft maintenance efficiency', 'aircraft maintenance and resource management attributes 'or 'effective planning and aircraft maintenance, and 'internal control and aircraft maintenance, etc., and explored to covers from Google Scholar, ProQuest, and Scopus, and other online resources. The study also justified of above summary literature gap by the most relevant theories such as stakeholder, agency, and resource-based theories accordingly. Based on this extensive review, the study developed a conceptual framework, where effective planning and internal control have moderating role on the relationship between the resource management attributes and aircraft maintenance efficiency in the aviation industry in the sultanate of Oman. The summary review findings of the study will fill the gap in the existing body knowledge especially prime factors affecting the attainment of aircraft maintenance efficiency, resource management attributes, effective planning and internal control and aircraft
\end{abstract}


maintenance in the aviation industry in the sultanate of Oman. The study recommends to justify this conceptual framework by empirical data from the in the aviation industry in the sultanate of Oman and draw a policy guideline for ensuring of determining of relevant factors that have cause and effects on the ensuring of aircraft maintenance efficiency in the aviation industry in Oman.

Keywords: Aircraft Maintenance, Resource Management, Effective Planning, Internal Control and Aviation Industry in Oman.

\section{INTRODUCTION}

Aircraft maintenance facilities is one of the very essential factor to enhance the aircraft productivities those facilities such as spears, human, and financial add to that the organizational factors in which will help to make the maintenance more efficient and safe because the safety is the priority part in maintenance in which the organization should take in consideration(Bowen, 2013). The aviation industry safety is one of the critical aspect of successful performance, moreover the personnel are the key players in all maintenance activities so it is not only carry out the activity but carry it with safely (Bowen, 2013).

There are numerous causes for the undesired extended aircraft downtime caused by ineffective maintenance. It has mentioned that up port of a huge armada of airplane postures critical challenges for a commerce in terms of accomplishing the different, and in a few ways clashing, objectives relating to support and operation costs and wanted benefit levels (Samaranayake \& Kiridena, 2012). Moreover, to reduce or minimise the extended aircraft downtime by improving the aircraft maintenance efficiency, it is mandatory to know the reasons that are helping the aircraft to remain under Hangar maintenance more than the estimated time of maintenance. The study also mentioned that there are two major stream of literature which focus in studying the problems which facing the heavy maintenance, he found that the first problem was focusing in the scheduling of the fleet of the aircraft, which known as "service scheduling" (Bird, 1976);(Sherif, 1980);(Elkodwa, 1996);(Chan, Cheung, Ip, Lu, \& Lai, 2005) and the other problems focusing in managing with perspectives of nitty gritty arranging and planning of exercises and support facilities such as materials, resources and maintenance personnel (Dijkstra, Kroon, van Nunen, \& Salomon, 1991);(Chan et al., 2005);(Alfares, 1999);(Chan et al., 2005);(Kilpi, Töyli, \& Vepsäläinen, 2009).

Since the research is dedicated studying the aviation sector in Oman, participant observational has been applied with a paradigm "inquiry from inside". This method requests from the research himself to spend some time in the organization itself to observe the real issue and collect all the needed data to be used for testing and evaluation. Many roles can be played in the participant observation method as a complete participant, researcher, complete observer, and observer as participant. Therefore, it is timely initiatives to investigate existing available literature for determining of relevant factors that have cause and effects on the ensuring of aircraft maintenance efficiency in the aviation industry in Oman.

Thus, the study justified of above summary literature gap by the most relevant theories such as stakeholder, agency, and resource-based theories accordingly. Based on this extensive review, the study proposed to develop a conceptual framework, where effective planning and internal control have moderating role on the relationship between the resource management attributes and aircraft maintenance efficiency in the aviation industry in the sultanate of Oman. 


\section{BACKGROUND OF THE STUDY}

\section{Historical development of aviation industries in Oman}

Oman's civil aviation was started in the year 1929 with a small airstrip made in Muscat. Initially was used for military purposes and occasionally for the flights of PETROLEUM Development Oman (PDO) Company. In 1960's Gulf Air started to operate its DC3 commercial flights to Oman. Oman started its own national carrier in the year 1970 as Oman International Services (OIS). The Sultanate of Oman became a member of the international Civil Aviation Organisation (ICAO) in the year 1973. Oman purchased Gulf Air's light aircraft division in the year 1977 and became Oman Air Services in the year 1981. A new airport was built at Salalah and OAS started operating regular domestic flights from Muscat to Salalah. The real development of Oman's civil aviation started when Oman Aviation Services (OAS) became Oman Air in the year 1993 and started to operate international services to Dubai and India. In the year 1996 Oman Joined the Arab Civil Aviation Organisation (ACAO) and in 1998 Oman Joined International Air Transport Association (IATA). Oman Air engaged CFM to provide engine maintenance services in Muscat. Airports were built in Adam, Butabul ,Buraimi , Dibba Al-Baya, Duqm , Fahud, Qarn Al Alam , Haima , Ibra, Ibri, Khasab , Lekhwair , Marmul , Mukhaizna , Nizwa, Ras al Hadd , Rustaq, Saiq, Salalah, Sohar, Sur and Yibal .

At present more than 550,000 aircraft overfly Oman's airspace. Civil aviation aircraft fly to more than 75 destinations from various airports in Oman. Flight developments at Muscat air terminal developed by $6.3 \%$ per year between 2013 and 2018 reaching 125,543 movements in 2018. Passenger traffic increased by $12 \%$ per year between 2013 and 2018 reaching 18 million passengers in Muscat International airport, Salalah Airport, Sohar Airport in 2018. Cargo traffic grew by $11 \%$ per year between 2013 and 2018 reaching 212,674 tons in 2018. The contribution of the direct and indirect civil aviation sector in the GDP of the Sultanate of Oman amounted to about 3.9 billion US dollars in 2018. In 2017 Salam Air, the first ever low-cost carrier in Oman started its operations. Oman Aviation group was founded in the year 2018 comprising of Oman Air, Oman Airports and Oman Aviation Services expanding the civil aviation sector in Oman. The civil Aviation industry in Oman employs more than 10,000 workforces from various countries and has potential to grow in future.

\section{METHODOLOGY OF THE STUDY}

As study aims to investigate existing available literature for determining of relevant factors that have cause and effects on the ensuring of aircraft maintenance efficiency in the aviation industry in Oman. Therefore, the study uses available sources of existing literature based on the four main keywords 'aircraft maintenance efficiency', 'aircraft maintenance and resource management attributes 'or 'effective planning and aircraft maintenance, and 'internal control and aircraft maintenance, etc., and explored to covers from Google Scholar, ProQuest, and Scopus, and other online resources.

\section{Empirical Reviews}

\section{REVIEW FINDINGS OF THE STUDY}

Many studies done by the previous researchers provided several theories that contributed extensively to maintenance resource management. (Miles, 2012) mentioned that since the late 1700s, scholars have talked about the issue of corporate proprietors contracting others as stewards of their riches. Directors of other people's cash cannot be anticipated to observe over it with the 
same enthusiasm as the proprietor, so administrative carelessness will continuously be show within the issues of a company. There are different theories related to this issue and try to explain the relation in detail. Agency theory is one of these theories which tries to study of the relationship between a client or "principle" and someone who performs a task on his/her behalf or "agent". This theory tries to show that the principle will act in his/her best interest even if his/her interests conflict with those of his/her agent ((Eisenhardt, 1989). On the other hand, the stakeholder theory justifies that the main priority of an organization should be its social performance and not only its financial performance. It stresses that increasing the wealth of shareholders is not an organization's primary function. On the contrary, stakeholders have an ethical responsibility to participate in the corporate decisions of an organization, and an organization must include them in discussions about the directions it is considering moving in (El Abboubi \& Nicolopoulou, 2012).

Explaining how the organizations maintain dominant positions in competitive environments was done by resource-based theory. This theory verifies that the resources in an organization have influences on its performance in addition to organizations compete against one another for resources (Priem \& Butler, 2001; Hoopes, Madsen, \& Walker, 2003; Peteraf \& Barney, 2003 ; Miles, 2012). It also assumes the basis of an organization's decisions about which resources to select and accumulate is composed of the following: economic rationality, limited information, biases and prejudices, and casual ambiguity (Anderson \& Richard). Other researchers focused on the important role of the human factors in aircraft maintenance. Shanmugam \& Paul Robert (2015) published a literature review on human factors in aircraft maintenance engineering. Study concluded that discipline in aircraft maintenance has made an extraordinary effect on airplane plan, operations, support, and standards. All previous are connected to shape the security behavior and culture in flying upkeep working environment. In any case, the survey unfurls monstrous potential for future investigate.

Virovac, Domitrović, \& Bazijanac (2017) explained that some papers presented the influence of human factor in one of the European aircraft maintenance organizations for widebody aircraft meant for commercial service. Their findings pointed out the occurrence of errors committed by employees' personality errors in communication, and errors in equipment, tools and the factor of working Environment. Based on their research paper the recommend creating a working climate within the aircraft maintenance organization, that will be stimulate for work and at the same time act preventively on the reduction of human Error. Recommendation for a continuous monitoring and analysis of human errors that occur in aircraft maintenance units were proposed by the study. Siddiqui et al. (2012) mentioned that over the previous twenty years, even has been an increasing recognition so human elements coaching do bear a significant affect over safety, especially within high-risk domains. The aviation industry has been at the forefront of this trend. Human calamity has been constantly identified as contributing in imitation of the championship of wind crashes given that the late 1970s. In the succeeding paragraphs, an attempt in accordance with make up a suit the use of various evaluation strategies in imitation of show that is been done.

Tooley (2013) spoke about the training and qualifications the engineers should have in order for them to work as aircraft maintenance staff. To perform a maintenance to the required standards, individual need to demonstrate maturity, commitment, integrity, and ability to see the job through, often under difficult circumstances. Once the maintenance tasks have been completed to the required standards, category B licensed engineer's certain approvals are permitted to signoff activities and sign the certificate of release to service (CRS). According to (Berto et al., 2011) human are the planning as an dynamic portion of the flight operations including pilots, support 
labor, discuss activity controllers, and others. Clearly, it's vital to be able to transfer on exceptionally talented individuals to maintain a strategic distance from mistakes that cause mischances or catastrophes in flight operations. It is at that point vital significance to put these individuals in authoritative and organized setting to ensure a reasonable level of proficient training. Human factors can be considered as human variables which have developed progressively prevalent till the level that the commercial flying industry realize that human blunder, rather than mechanical disappointment, underlies most flying accidents and episodes. It is important to note that human factors play an important role in all industries and aviation is not an exemption. The human errors may incur heavy losses in lives and machines, so it's been obvious that human factors have a significant effect in maintenance-related aircraft accidents. It is worth mentioning studies and research that have proven that human error is the main cause of accidents in various industries with global consequences such as aviation and medicine. Based on these discoveries, organizations involved in these industries have developed training programs for employees on a large scale, in order to prevent or reduce these errors and thus mitigate their impact on beneficiaries from the service of these organizations. Therefore, this paper was discussing the importance of the human factors training in aviation industry also mention the errors caused by human factors in aircraft maintenance which certified as 147 according to the European Aviation safety Authority standards. By comparing the previous mentioned theories related to maintenance resource management, resource-based theory can be considered as the best choice among them to be the base of the conducted research. The reason for choosing this theory is the resources of an organization possess influence on its performance. In more detail, RBT accepts that organizational choices to choose and collect assets are financially levelheaded and subject to constrained data, predispositions and biases, and causal ambiguity (Teece, Pisano, \& Shuen, 1997). Causal ambiguity means that it isn't known precisely how an asset leads to above-average execution for an Organization. A resource is characterized as anything that can be thought of as a quality for an organization. Assets incorporate any unmistakable or intangible resources that are semi for all time tied to the organization. Resource-based theory posits that an organization can achieve sustainable competitive advantage by controlling resources that are valuable, rare, imperfectly imitable, and non-substitutable. Your task as a manager is to help your organization use resources more effectively and efficiently than your competition over time.

\section{Theoretical reviews}

Previously number of literature and researchers have provided a number of theories contributed extensively to maintenance resource management for example (Miles, 2012)mentioned in his book since the late 1700 s, scholars have talked about the issue of corporate proprietors contracting others as stewards of their riches. Directors of other people's cash cannot be anticipated to observe over it with the same enthusiasm as the proprietor, so administrative carelessness will continuously be show within the issues of a company (Smith, 1776/1952)(Miles, 2012).

\section{Agency theory}

Agency theory revolves around the study of the relationship between a client or "principle" and someone who performs a task on his/her behalf or "agent." Agency relationships have to do with the delegation of authority, and can be observed in a variety of fields whether medicine (doctorpatient), politics (elected official- constituents), law (lawyer-client), insurance (insurance company-insured), real estate (real estate agent- seller or buyer) and so on. Agency theory argues that in this dynamic, the principle will act in his/her best interest even if his/her interests' conflict 
with those of his/her agent. In a corporate setting, this implies a company's management will act in its own best interests first rather than those of the shareholders it is to be working on behalf of. Scholars such as(Eisenhardt, 1989), and (Miles, 2012)have written on these issues.

\section{Stake holder theory}

Stakeholder theory argues that a main priority of an organization should be its social performance and not only it's financial performance. It stresses that increasing the wealth of shareholders is not an organization's primary function. On the contrary, stakeholders have an ethical responsibility to participate in the corporate decisions of an organization, and an organization has an obligation to include them in discussions about the directions it is considering moving in. It has been argued this sort of relationship results in the organization having a competitive advantage and thus is beneficial for both the organization and its shareholders (El Abboubi \& Nicolopoulou, 2012).

\section{Resource-based theory}

One of the objectives of resource-theory is to explain how organizations manage to maintain dominant positions in competitive environments (Hoopes, Madsen, \& Walker, 2003) According to resource-based theory, the resources an organization possesses have an influence on its performance (Peteraf \& Barney, 2003) (2012 (Miles, 2012), and organizations compete against one another for resources (Priem \& Butler, 2001) Cited by (Miles, 2012) An organization assesses and categorizes other organizations as competitors based on factors including similarity of products, resources, capabilities, and substitutes (Priem \& Butler, 2001)Cited by(Miles, 2012). There are two main assumptions in this theory: 1.) resources are not equally distributed among all organizations and 2.) Resources may have limited mobility and so this disequilibrium of resources among organizations can be a long-term problem (Peteraf \& Barney, 2003) Cited by(Miles, 2012). It also assumes the basis of an organization's decisions about which resources to select and accumulate is composed of the following: economic rationality, limited information, biases and prejudices and casual ambiguity (Anderson \& Richard) Based on the objective of this study and research, which aims to measure the effects of effective planning and proper control of the relationship between the management of the sources of maintenance and aviation maintenance in the aviation industry in Oman, the appropriate theory for the application in this research is resource- based theory.

This study and research aim to measure the effects of effective planning and proper control of the relationship between the (management of the sources of maintenance?) and the aviation maintenance in the aviation industry in Oman. Based on this objective, resource-based theory is the most appropriate framework for analysis. This is because the resources an organization possesses have an influence on its performance (Peteraf \& Barney, 2003) Cited by Jeffery A (2012).

\section{The Resource-based Theory (RBT)}

The central thought in resource-based hypothesis is that organizations compete against others on the premise of their assets and capabilities (Peteraf \& Barney, 2003) Cited by(Miles, 2012). An organization's competitors can be distinguished by the likeness of their items, assets, capabilities, and substitutes (Peteraf \& Barney, 2003) Cited by(Miles, 2012). The hypothesis accept that organizational choices to choose and collect assets are financially levelheaded and subject to constrained data, predispositions and biases, and causal ambiguity(Teece, Pisano, \& Shuen, 1997) Cited by)(Miles, 2012).. Causal ambiguity means that it isn't known precisely how a asset leads to 
above-average execution for an Organization. A resource is characterized as anything that can be thought of as a quality for an organization (Wernerfelt, 1984)) Cited by. (Miles, 2012)).. Assets incorporate any unmistakable or intangible resources that are semi for all time tied to the organization. Resource-based theory posits that an organization can achieve sustainable competitive advantage by controlling resources that are valuable, rare, imperfectly imitable, and non-substitutable. Your task as a manager is to help your organization use resources more effectively and efficiently than your competition over time.

However, the RBT has been criticized by many researchers as being inherently internally focused. It has failed to explain how resources are developed and deployed to achieve competitive and inability to consider the impact of dynamic market environments. Due to this criticisms, RBT gradually evolved towards the belief that resources are not sufficient alone to generate superior performance and distinctive competitive basis for companies being inherently internally focused and its limitation for dealing with current complex and turbulent marketplaces issues (Kozlenkova, Samaha, \& Palmatier, 2014; Roach, Ryman, Jones, \& Ryman, 2018; Teece et al., 1997). Therefore, and in response to the limitations of the RBT, the dynamic capabilities view (DCV) has been offered as a more suitable foundation theory to coop with such complex and turbulent markets, which need the continual renewal and reconfiguration of the organization and its resources level (Ambrosini, Bowman, \& Collier, 2009; Roach et al., 2018; Teece et al., 1997) According to (Teece et al., 1997), the energetic capabilities see looks at the sources and strategies of riches creation and capture by private firms that working in situations of quick innovative alter, endeavors to recognize and find capabilities that can drive the firm to progress its execution and accomplish a maintainable competitive advantage and clarifies how these energetic capabilities can offer assistance in superior asset allotment within the firm (Teece et al., 1997). In other words, DCV sets that the capabilities in which firms' assets are created and sent in ways that able coordinating the firm's advertise environment and clarifies its execution change over time (Ambrosini et al., 2009).

\section{Literature GAP}

After analyzing and studying all the different gaps that might be faced in the previous conducted studies, the current research come up with some of the points that should be tackled in the next step of the research. The following study should help to enhance awareness among the aircraft maintenance organizations in Oman. Initiating the effective usage of aircraft maintenance resources for minimizing the downtime or the aircraft being on the ground for a long time should be considered as one of the critical works in the aviation industry. The study also should concentrate on building the road map to various departments on the effective management of material, manpower, resources, and facilities. One of the main points that come up out of this extensive research is that increasing the availability of aircraft for operation by reducing the downtime. At the end, the aviation industries should minimize the influencing factors of aircraft downtime and emphasize the importance of proper planning and control in aircraft maintenance organizations.

\section{DEVELOPMENT OF CONCEPTUAL RESEARCH FRAMEWORK}

Based on reviewing several related and core literatures and different theories to meet the study objectives and questions, the framework of this study was formed. The main objective of the proposed framework is to focus on the moderating impacts of effective planning and control on the relationship of resource management attributes and aircraft maintenance in the aviation industry in the sultanate of Oman. The following framework proposed to solve aviation's talent 
gap problem by studying the different core variables as the independent variables, dependent variables and, and moderating variable. This study focused in the effect of the independent variables in aircraft maintenance efficiency in aviation industry in the Sultanate of Oman. The independent variables (IVs) are summarized in five main areas which are Aircraft maintenance facilities, spear parts management, organizational factors, financial allocation and human factors as those are the main factors which have a direct effect and big influence in maintenance efficiency. The study has a moderating Variables (MV) which is planning and control in which I have the influence in all independent variables (IVs). Finally, the study Dependent variables (DV) aircraft maintenance which must be more efficient, safe and with the aviation authority's regulation. Furthermore, this study will be carried out in the sultanate of Oman on aviation industry, some selected air liners and fleets such as Oman air, royal air force of Oman and royal Oman police by focusing in the following posts which directly manage the maintenance activities in the maintenance section.
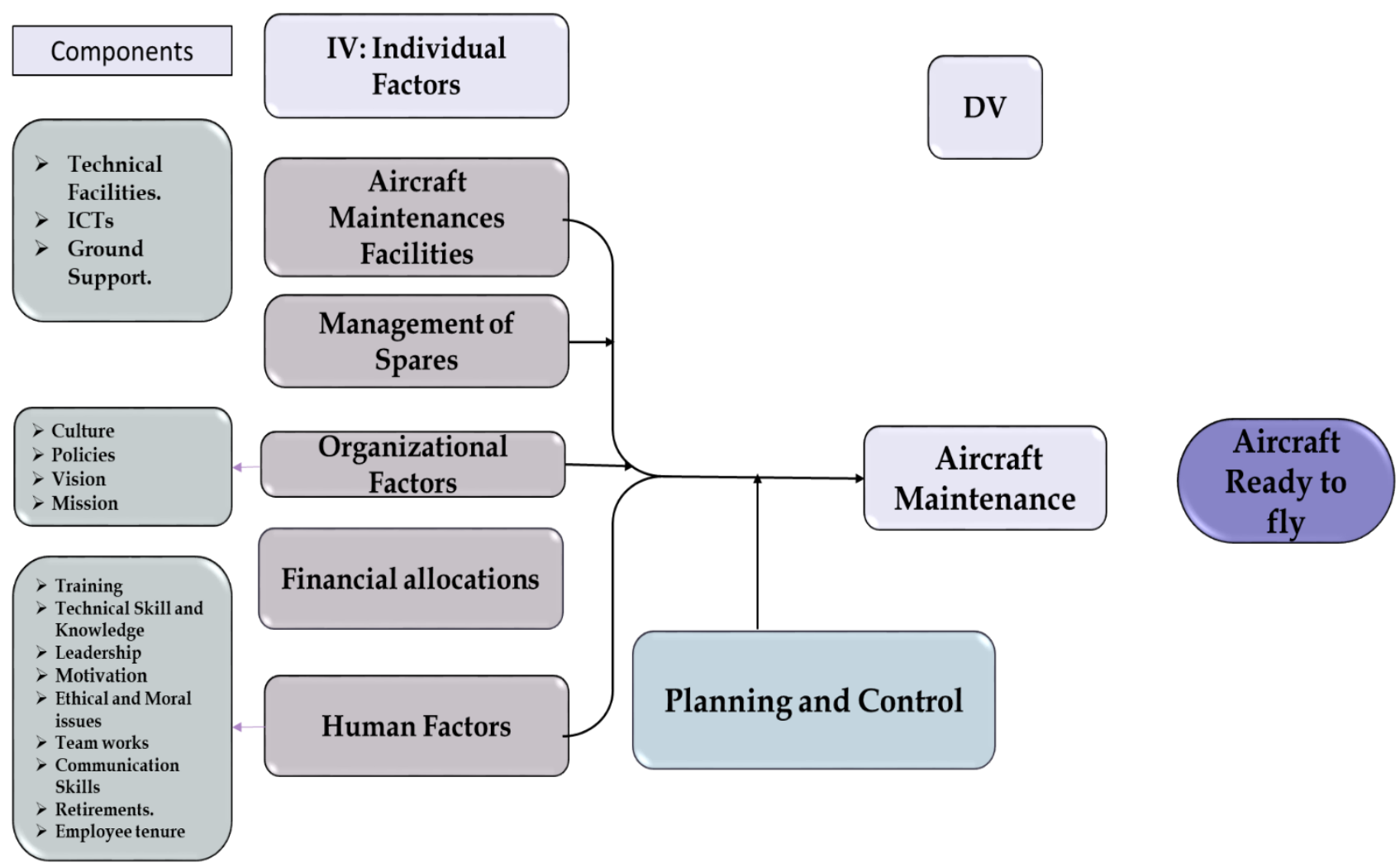

Figure 1. Proposed framework

The independent variable of this research in general meaning is the maintenance resource, this variable has been mentioned earlier as one of the major ones in the studied literatures. There are five independent factors of aircraft maintenance, which will be covered and discussed in this study, those factors are Aircraft maintenance facilities, management of spares, organizational factors, financial allocation, and human factors.

The dependent variable of this study is the Aircraft maintenance, where this maintenance would not be completed without supporting elements which are the independent variables (Joshi, 2004). Joshi (2004) mentioned that the important factor to justify the maintenance implementation 
is the revising of resource allocation. Having all resources required for the maintenance and proper allocation and use of them will make the maintenance more efficient. Another variable that will be covered in this study framework is one variable related to the mediating variable called planning and control. This variable has both positive and negative effects (Sherwin, 2000). Sherwin (2000) pointed out in the study that in all engineering there is a demand for this variable. To meet that demand, a planning function should be flexible and also have the ability to adjust to the sequence in which it carries out the work. Also, the engineering work is complex and expensive so its need to be controlled to meet the objectives were set during the plane stage.

\section{CONCLUSION AND RECOMMENDATIONS}

As it was the aims to investigate existing available literature for determining of relevant factors that have cause and effects on the ensuring of aircraft maintenance efficiency in the aviation industry in Oman. The study revealed from analyzing of the review findings that there are different gaps in existing literature and the current research come up with some of the points that should be tackled in the next step of the research. The following study also identified the effective usage of aircraft maintenance resources for minimizing the downtime or the aircraft being on the ground for a long time should be considered as one of the critical works in the aviation industry.

The study also justified of above summary literature gap by the most relevant theories such as stakeholder, agency, and resource-based theories accordingly. Based on this extensive review, the study developed a conceptual framework, where effective planning and internal control have moderating role on the relationship between the resource management attributes and aircraft maintenance efficiency in the aviation industry in the sultanate of Oman. The summary review findings of the study will fill the gap in the existing body knowledge especially prime factors affecting the attainment of aircraft maintenance efficiency, resource management attributes, effective planning and internal control and aircraft maintenance in the aviation industry in the sultanate of Oman.

\section{REFERENCES}

Adams, L., \& Courtney, J. (2004). Achieving Relevance in IS Research via the DAGS Framework. 37th Hawaii International Conference on System Sciences, Big Island, Hawaii: IEEE.

Amaro, S., Abrantes, J. L., \& Seabra, C. (2015b). Comparing CB-SEM and PLS-SEM results: an empirical example.

Anderson, E., \& Richard, L. Oliver. (1987). Perspectives on Behavior-Based Versus OutcomeBased Salesforce Control Systems. Journal of Marketing, 51, 76-88.

Chatterjee, S., Tulu, B., Abhichandani, T., and Li (2005). H. SIP-based Enterprise Converged Network for Voice/Video over IP: Implementation and Evaluation of Components. IEEE Journal on Selected Areas in Communications - Recent Advances in Managing Enterprise Network Services, 23, 10.

Eisenhardt, K. M. (1989). Agency theory: An assessment and review. Academy of management review, 14(1), 57-74.

El Abboubi, M., \& Nicolopoulou, K. (2012). International social-related accountability standards: using ANT towards a multi-stakeholder analysis.M@n@gement, 15(4), 392-414.

Evered, R. and Reis Louis, M. (2001) Alternative Perspectives in the Organizational Sciences: 'Inquiry from the Inside' And 'Inquiry from the Outside, in Academy of Management Review, 6(3), 385-395. 
Gallagher, D., Ting, L., \& Palmer, A. (2008). A journey into the unknown; taking the fear out of structural equation modeling with AMOS for the first-time user. The Marketing Review, $8(3), 255-275$.

Gefen, D., Rigdon, E. E., \& Straub, D. (2011). Editor's comments: an update and extension to SEM guidelines for administrative and social science research. Mis Quarterly, iii-xiv.

Hoopes, D. G., Madsen, T. L., \& Walker, G. (2003). Guest editors' introduction to the special issue: why is there a resource-based view? Toward a theory of competitive heterogeneity. Strategic Management Journal, 24(10), 889-902.

Miles, J. A. (2012). Management and organization theory: A Jossey-Bass reader (Vol. 9): John Wiley \& Sons.

Patton, M.Q. (2002). Qualitative Research \& Evaluation Methods, Sage publications,USA

Peteraf, M. A., \& Barney, J. B. (2003). Unraveling the resource-based tangle. Managerial and decision economics, 24(4), 309-323.

Priem, R. L., \& Butler, J. E. (2001). Is the resource-based "view" a useful perspective for strategic management research? Academy of management review, 26(1), 22-40.

Persson, S. (2004). Qualitative Methods in Software Engineering.

Sherwin, D. (2000). A review of overall models for maintenance management. Journal of Quality in Maintenance Engineering, 6(3), 138-164.

Teece, D. J., Pisano, G., \& Shuen, A. (1997). Dynamic capabilities and strategic management. Strategic Management Journal, 18(7), 509-533.

\section{Copyrights}

Copyright for this article is retained by the author(s), with first publication rights granted to the journal. This is an open-access article distributed under the terms and conditions of the Creative Commons Attribution license (http://creativecommons.org/licenses/by/4.0/). 